\title{
Folic acid content of beetroot leaf and root by different growing stages and genotypes
}

\author{
Tímea Rubóczki - Mária Takácsné Hájos \\ University of Debrecen, Faculty of Agricultural and Food Sciences and Environmental Management \\ Institute of Horticultural Science \\ H-4032 Debrecen, Böszörményi Street 138. \\ ruboczkit@agr.unideb.hu
}

\section{SUMMARY}

\begin{abstract}
An increasing interest has been observed of beetroot leaf as a salad component due to recent studies focusing on their nutritional value. The randomized field experiment was carried out on lowland chernozem soil with 6 varieties, 3 replications and 2 sowing dates. Sampling was performed on 23 of August 2018 at the stage of 30 and 50 days of vegetation, where leaf (30 and 50 days) and root (50 days) were collected. Total dry matter, folic acid and nitrate content were evaluated.

The results of this investigation show that higher total dry matter content was measured in the root (8.47-10.30\%) compared to the leaf in both developmental stages (6.47-9.20\%). Nevertheless, higher folic acid content was found in the young leaves of 30 and 50 days of development (58.77-113.86 $\mu \mathrm{g} 100 \mathrm{~g}^{-1}$ ). Among the examined varieties, Bonel has presented great amount of folic acid not only in the leaves $\left(99.35-113.61 \mu \mathrm{g} 100 \mathrm{~g}^{-1}\right)$, but also in the root $\left(89.99 \mu \mathrm{g} 100 \mathrm{~g}^{-1}\right)$. Finally, lower nitrate content was found in Libero (316.16 mg $\left.\mathrm{kg}^{-1}\right)$ at 30 days and in Akela (340.41 $\left.\mathrm{mg} \mathrm{kg}^{-1}\right)$ at 50 days of development. Thereby, fresh consumption of beetroot leaves are highly recommended.
\end{abstract}

Keywords: beetroot leaf, beetroot root, folic acid content, growing stages, nitrate content, total dry matter content

\section{INTRODUCTION}

An increasing attention has been observed of beetroot leaf as a salad component. Beetroot (Beta vulgaris ssp. esculenta var. rubra L.) is mainly grown for its root, however, in ancient times the leaves were used for curative purposes. Recent studies have pointed out the importance of beetroot leaves. First of all, the leafy vegetables like spinach, sorrel or beetroot contain high amount of mineral elements, phenolic compounds, folic acid (Chew et al., 2012; Delchier et al., 2016) and nitrate in moderate amount. Secondly, the leaves and the stalk of the beetroot can be a good source of antioxidants which leads us to eat the whole plant and reduce food waste (Biondo et al., 2014; Lorizola et al., 2018).

The importance of folic acid (or vitamin $\mathrm{B}_{9}$ ) lies in the ability to prevent of neural tube defects (NTDs) (Ashfield-Watt et al., 2002), cardiovascular and neurodegenerative diseases (Moat et al., 2004), colorectal cancers (Jennings and Willis, 2015) and Alzheimer's disease (Snowdon et al., 2000; Yoo et al., 2000). Besides folic acid, recent studies have highlighted the role of nitrate derived from beetroots in reducing blood pressure (Jajja et al., 2014).

In Hungary, beetroot is mainly produced as second cultivation, therefore the sowing time starts at the end of June or beginning of July. The common varieties are multigerm types, thus, thinning has to be done at the stage of 2 to 4 leaves. At this time, the soft leaves give us a good alternative for fresh salad. Later on the vegetation period, the leaves become fibrous, thereby consumption of them are less pleasant. Despite of the nutritional values of leaves, the thinned leaves which are not used for consumption are going to be animal feed or food waste.
However, leafy vegetables are rich in folates, reliable data on folic acid content of beetroot leaf and root are still lacking, especially with regard to the effects of variety differences, growing areas as well as developmental stages. Thus, the main objective of this experiment was to determine the proximate amount of total dry matter, folic acid and nitrate of beetroot leaves at different stages of development (30 and 50 days) in order to consider the potential use of their leaves as food. Additionally, the root was evaluated at the stage of 50 days when its size was measurable and edible.

\section{MATERIAL AND METHODS}

The experiment was conducted at the University of Debrecen, Farm and Regional Research Institute, Botanical and Exhibition Garden. Sowing was performed two times (27 of June and 19 of July 2018) due to lack of uniform germination. The size of parcels were $5 \mathrm{~m} \times 0.35 \mathrm{~m}$. The following 6 varieties were observed: four spherical type - Bonel, Libero, Larka, Akela and two cylindrical type - Carillon, Lomako.

The experiment was carried out on lowland chernozem soil which had good parameters for beetroot cultivation as it is depicted in Table 1 .

The daily temperature and the natural precipitation were measured by the Agricultural Laboratory Centre, University of Debrecen. The average temperature was uniform except during the first week of July where the values raised from 15 to $25^{\circ} \mathrm{C}$ (Figure 1). In August, the maximum temperature reached $35^{\circ} \mathrm{C}$ several times, however, no damage was found in the beetroot plants.

Figure 2 shows the daily precipitation during the vegetation period which had to be completed with drip irrigation (20-25 $\mathrm{mm}$ occasionally) for the proper development. 
Soil analysis of the experimental field (Debrecen, 2018)

\begin{tabular}{lc}
\hline \multicolumn{1}{c}{ Analysed parameter (unit of measurement) } & Amount \\
\hline $\mathrm{pH}(\mathrm{KCL})$ & 7.09 \\
Plasticity index of Arany K & 39 \\
Total water-soluble salt\% (w/w) & 0.04 \\
$\mathrm{CaCO}_{3} \%(\mathrm{w} / \mathrm{w})$ & 0.926 \\
$\mathrm{Humus} \%(\mathrm{w} / \mathrm{w})$ & 2.59 \\
$\mathrm{AL}-$ soluble $\mathrm{P}_{2} \mathrm{O}_{5}\left(\mathrm{mg} \mathrm{kg}^{-1}\right)$ & 659 \\
$\mathrm{AL}-$ soluble $\mathrm{K}_{2} \mathrm{O}\left(\mathrm{mg} \mathrm{kg}^{-1}\right)$ & 318 \\
$\mathrm{KCL}-$ soluble $\mathrm{NO}_{3}^{-}+\mathrm{NO}_{2}^{-}-$Nitrogen $\left(\mathrm{mg} \mathrm{kg}^{-1}\right)$ & 5.68 \\
\hline
\end{tabular}

Source: Agricultural Laboratory Centre, University of Debrecen (2018) - The values are expressed in air dry matter.

Figure 1: The temperature values of the vegetation period (Debrecen, 2018)

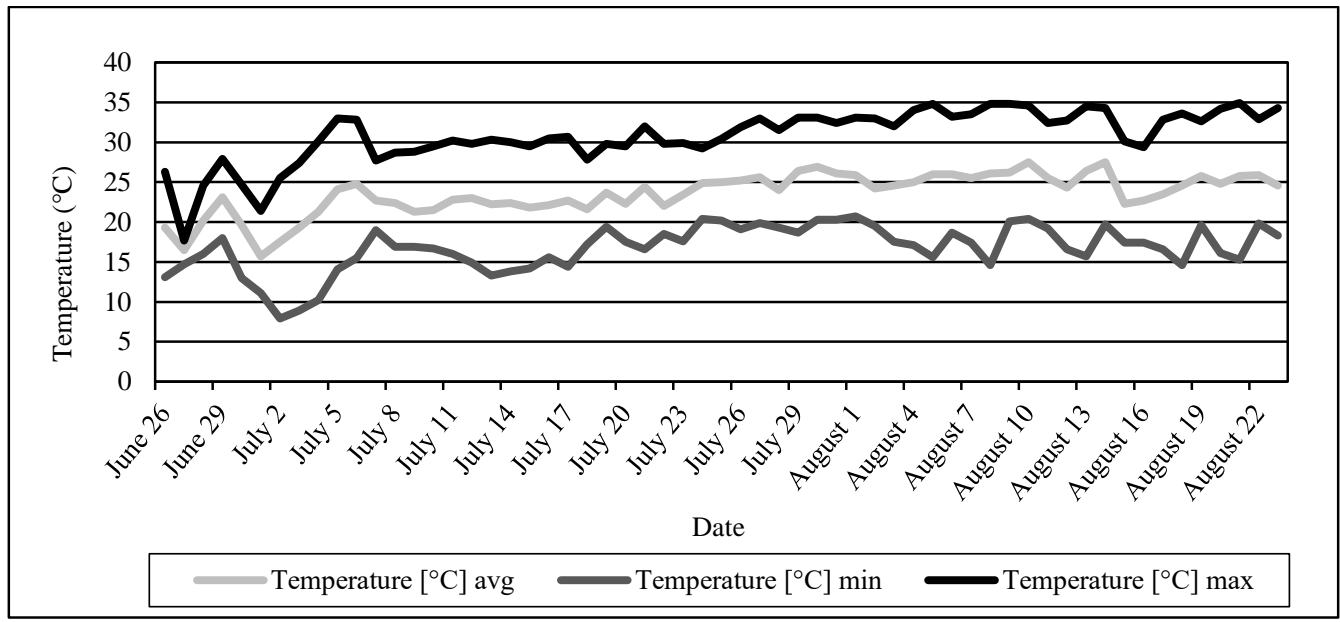

Source: Agrometeorological and Agro-ecological Monitoring Centre AKIT-DTTI, University of Debrecen (2018)

Figure 2: The precipitation during the vegetation period (Debrecen, 2018)

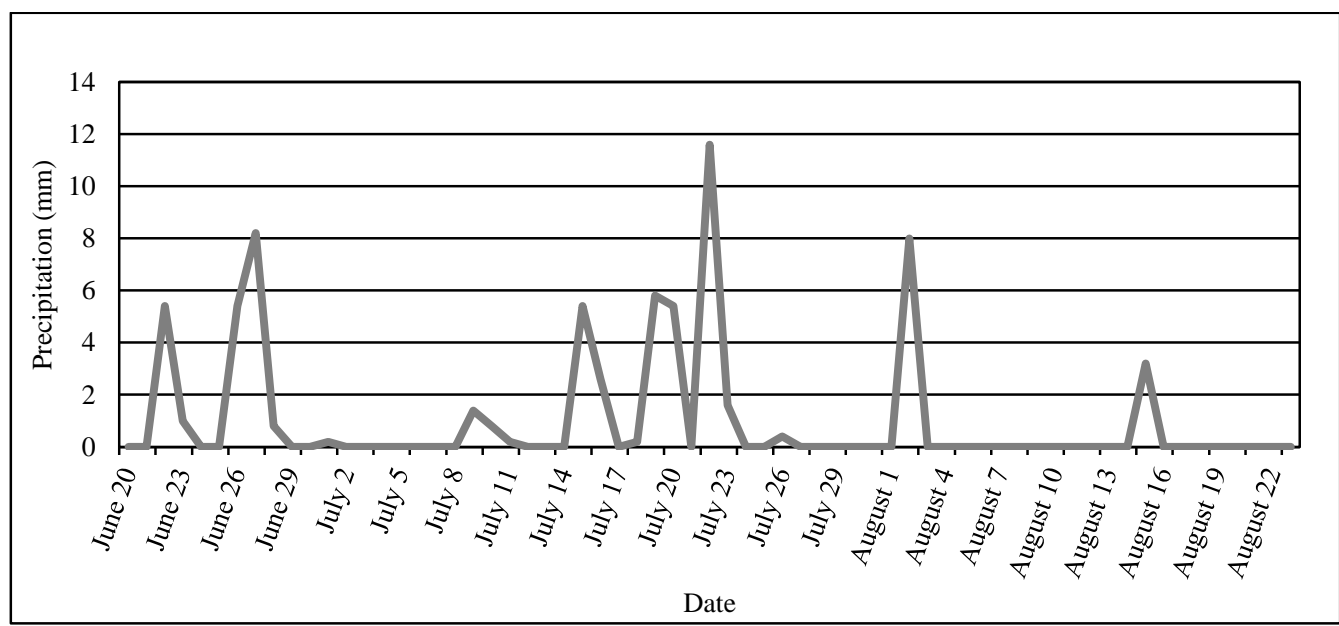

Source: Agrometeorological and Agro-ecological Monitoring Centre AKIT-DTTI, University of Debrecen (2018)

The examined varieties are multigerm genotypes, therefore the young leaves were thinned on 19 of July and 6 of August at the stage of 2 to 4 leaves.

The samples were prepared on 23 of August, which was at the stage of 30 and 50 days of vegetation (days after germination). For the sampling, 10 representative plants were chosen from 3 randomised blocks $(n>30$ per block) from each variety. After that, the plants were split in 2 random groups in order to have 2 samples per variety. 
Regarding to measurements, they were performed at the Agricultural Laboratory Centre, University of Debrecen and were the following (expressed in fresh weight):

- Total dry matter content $(\%) \pm 0.2(\mathrm{~m} / \mathrm{m}) \%$ - drying on $105{ }^{\circ} \mathrm{C}$ by MSZ-08-1783-1:1983 chapter 2 protocol

- Folic acid content $\left(\mu \mathrm{g} 100 \mathrm{~g}^{-1}\right) \pm 10 \% \mathrm{R}-\mathrm{R}$ Biopharm VitaFast Folic acid P1001 by MSZ EN 14131:2003 protocol

- Nitrate content $\left(\mathrm{mg} \mathrm{kg}^{-1}\right) \pm 5 \% \mathrm{R}-$ CONTIFLOW method by MSZ EN 12014-7:1999 chapter 6 protocol

\section{RESULTS AND DISCUSSION}

\section{Total dry matter content}

Additionally to sugar, other components as dietary fibres are measured by total dry matter content. Differences were found not only between the varieties, but also between the leaf and root at the stage of 30 and 50 days (Figure 3 ).

Figure 3: Total dry matter content (\%) of beetroot leaf and root at different growing stages (Debrecen, 2018)

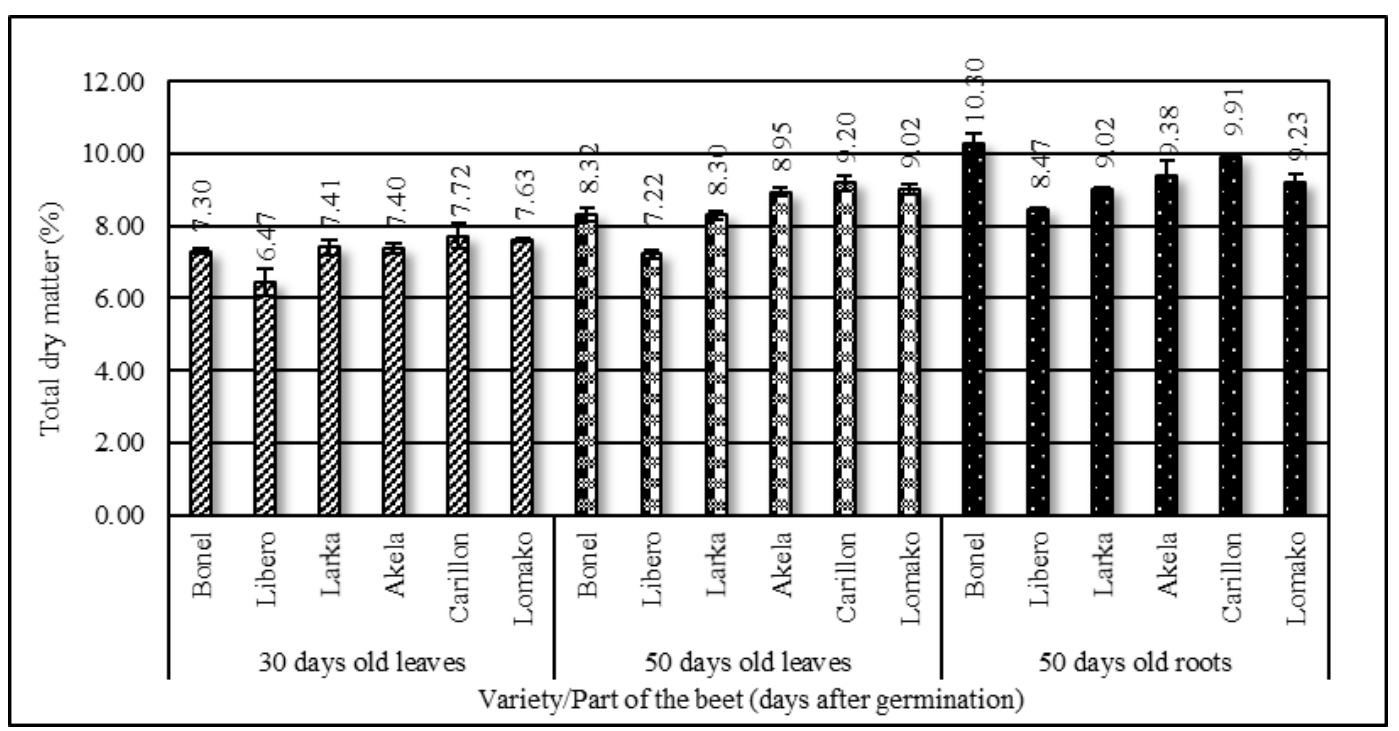

Libero has showed the lowest values within the varieties in leaf (6.47-7.22\%) and root (8.47\%). On the other hand, Bonel and Carillon had the highest total dry matter content $(\%)$ in the 50 days old roots (10.30$9.91 \%)$. Besides of the roots, the values of the leaves were high as well in the mentioned varieties.

\section{Folic acid content}

The microbiological assay is still one of the most common method for determination of folate content of foods (Jastrebova et al., 2003), therefore, in the present study Lactobacillus rhamnosus was used to determine the total folic acid content of beetroot leaf and root. Data of this vitamin content are presented in Figure 4 , where the values are expressed in fresh weight.

From the figure, it can be seen, that beetroot leaves of different stages (30 and 50 days) contain higher amount of folic acid than the 50 days old root. However, great differences with varied SD values can be obtained among varieties. Considering the leaves, Akela has less folic acid content with 58.77 (30 days) and 75.14 (50 days) $\mu \mathrm{g} 100 \mathrm{~g}^{-1}$ in the leaf. Besides, other varieties showed values above $80 \mu \mathrm{g} 100 \mathrm{~g}^{-1}$. Moreover, with the exception of Lomako, values above $40 \mu \mathrm{g}$ $100 \mathrm{~g}^{-1}$ were evaluated in root, though other studies have reported even less amount $\left(29.4 \mu \mathrm{g} 100 \mathrm{~g}^{-1}\right)$ in beetroot (Delchier et al., 2016). The highest folic acid content of root was measured in Bonel $\left(89.99 \mu \mathrm{g} 100 \mathrm{~g}^{-1}\right)$.

Researchers have observed folic acid values based

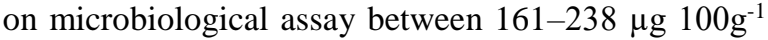
(Houlihan et al., 2011) and $302 \mu \mathrm{g} 100 \mathrm{~g}^{-1}$ (Iwatani et al., 2003) in spinach. Thereby, the soft leaves (30 and 50 days old) of beetroot can be considered as well as a good source of folate (vitamin $\mathrm{B}_{9}$ ) intake. At this time, the beetroot leaf and stem can be mixed with other species like spinach in order to have a nutritious and pleasant meal. 
Figure 4: Folic acid content $\left(\boldsymbol{\mu g} \mathbf{1 0 0 \mathrm { g } ^ { - 1 }}\right.$ fresh weight) of beetroot leaf and root at different growing stages (Debrecen, 2018)

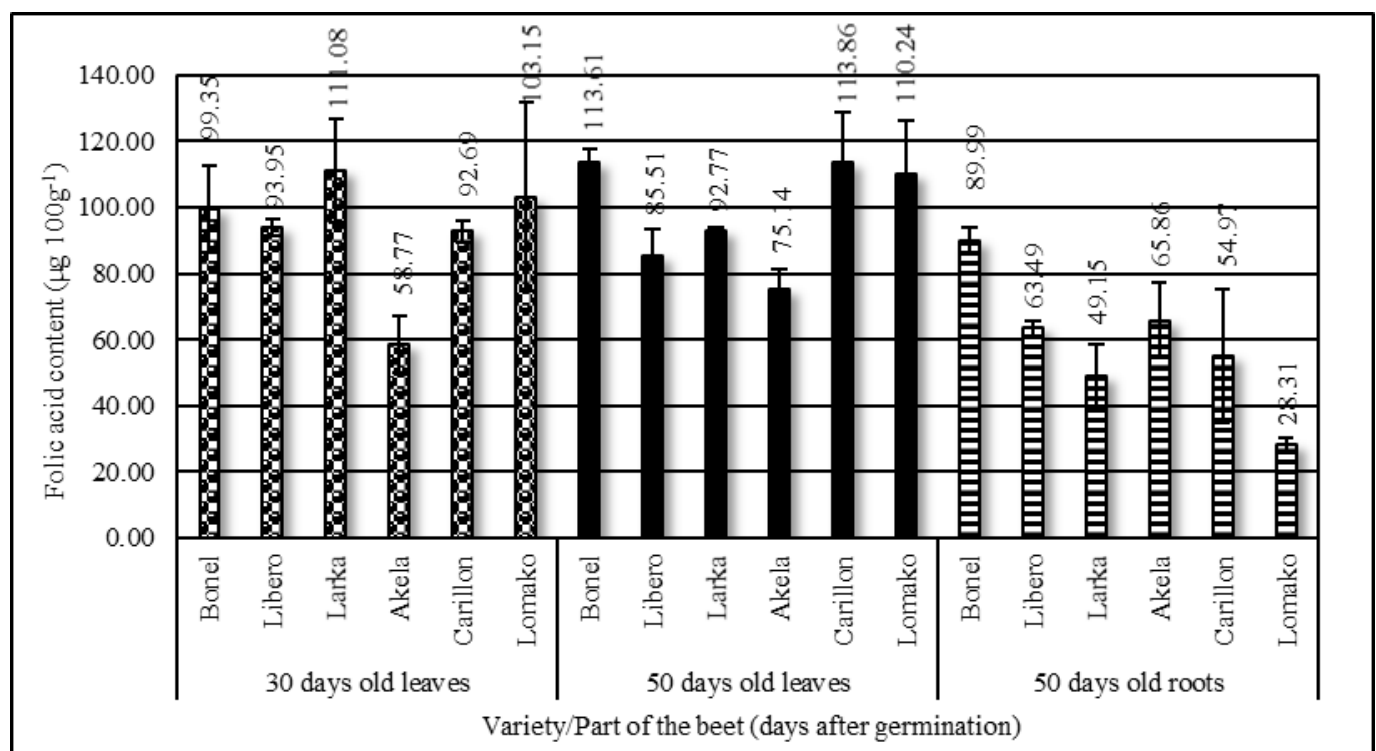

\section{Nitrate content}

Studies have reported that nitrate derived from beetroots can reduce blood pressure (Jajja et al., 2014), however, high amount of it can be harmful for the human body. Therefore, measuring the amount of nitrate is important in the case of fresh consumption. Samples of 30 and 50 days old leaves were evaluated for this parameter (Figure 5).

Figure 5: Nitrate content ( $\mathrm{mg} \mathrm{kg}^{-1}$ fresh weight) of beetroot leaf at different developmental stages (Debrecen, 2018)

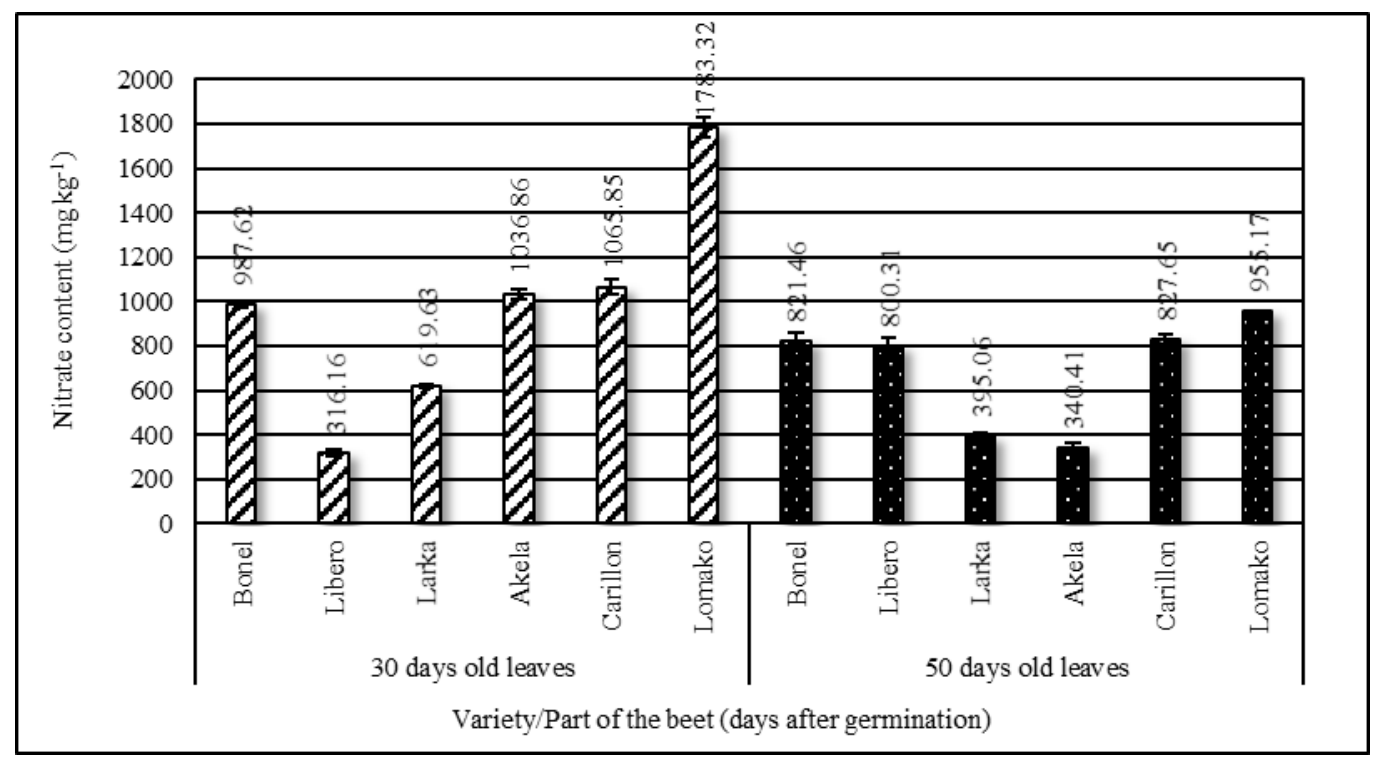

It is apparent from this figure that great differences can be found between varieties and different stages of development. Lomako and Carillon (cylindrical types) have showed the highest amount of nitrate (1783.32 and $1065.85 \mathrm{mg} \mathrm{kg}^{-1}$, respectively) at the 30 days of development. Similar trend can be obtained with these varieties at 50 days (955.17 and $827.65 \mathrm{mg} \mathrm{kg}^{-1}$, respectively). Lower nitrate content was found in Libero (316.16 $\mathrm{mg} \mathrm{kg}^{-1}$ ) at 30 days and in Akela (340.41 $\mathrm{mg} \mathrm{kg}^{-1}$ ) at 50 days of development.

\section{CONCLUSION}

The experiment was carried out on lowland chernozem soil with 6 varieties, 3 replications and 2 sowing dates. Sampling was performed on 23 of August 2018 at the stage of 30 and 50 days of vegetation, where leaf (30 and 50 days) and root (50 days) were collected. The main objective of this experiment was to determine the approximate amount of total dry matter, folic acid and nitrate of beetroot 
leaves at different stages of development (30 and 50 days) in order to consider the potential use of their leaves as food. Additionally, the root was evaluated at the stage of 50 days when its size was measurable and edible.

The results of this investigation show that higher total dry matter content was measured in the root (8.47$10.30 \%$ ) compare to the leaf in both developmental stages (6.47-9.20\%). Nevertheless, higher folic acid content was found in the young leaves of 30 and 50 days of development (58.77-113.86 $\left.\mu \mathrm{g} \quad 100 \mathrm{~g}^{-1}\right)$. Among varieties, Bonel has presented great amount of folic acid not only in the leaves (99.35-113.61 $\mu \mathrm{g}$

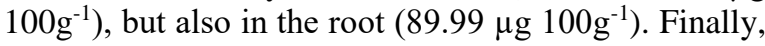

lower nitrate content was found in Libero $(316.16 \mathrm{mg}$ $\mathrm{kg}^{-1}$ ) at 30 days and in Akela (340.41 $\left.\mathrm{mg} \mathrm{kg}^{-1}\right)$ at 50 days of development. Thereby, fresh consumption of beetroot leaves as salad components are highly recommended.

\section{ACKNOWLEDGMENTS}

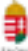

This study was supported by the ÚNKP-18-3 New National Excellence Program of the Ministry of Human Capacities.

\section{REFERENCES}

Ashfield-Watt, P. A. L.-Pullin, C. H.-Whiting, J. M.-Clark, Z E.-Moat, S. J.-Newcombe, R. G.-Burr, M. L.-Lewis, M. J.Powers, H. J.-McDowell, I. F. W. (2002): Methylenetetrahydrofolate reductase $677 \mathrm{C}->\mathrm{T}$ genotype modulates homocysteine responses to a folate-rich diet or a lowdose folic acid supplement: a randomized controlled trial. American Journal of Clinical Nutrition 76, 180-186.

Biondo, P. B. F.-Boeing, J. S.-Barizão, É. O.-De Souza, N. E.Matsushita, M.-De Oliveira, C. C.-Boroski, M.-Visentainer, J. V. (2014): Evaluation of beetroot (Beta vulgaris L.) leaves during its developmental stages: a chemical composition study. Food Science and Technology, 94-101.

Chawla, H.-Parle, M.-Sharma, K.-Yadav, M. (2016): Beetroot: A Health Promoting Functional Food. Inventi Rapid: Nutraceuticals, 1-5.

Chew, S. C.-Loh, S. P.-Khor, G. L. (2012): Determination of folate content in commonly consumed Malaysian foods. International Food Research Journal, 189-197.

Delchier, N.-Herbig, A.-L.-Rychlik, M.-Renard, C. M. G. C. (2016): Folates in Fruits and Vegetables: Contents, Processing, and Stability. Comprehensive Reviews in Food Science and Food Safety, 506-528.

Houlihan, A.-Pyke, M.-Scheelings, P.-Graham, G.-Eaglesham, G.O'Hare, T.-Wong, L.-Puwastien, P.-Jongjitsin, W. (2011): Folate Content of Asian Vegetables. Canberra: Australian Government: Rural Industries Research and Development Corporation.
Jajja, A.-Sutyarjoko, A.-Lara, J.-Rennie, K.-Brandt, K.-Qadir, O.Siervo, M. (2014): Beetroot supplementation lowers daily systolic blood pressure in older, overweight subjects. Nutrition Research 34, 868-875.

Jastrebova, J.-Witthöft, C.-Grahn, A.-Svensson, U.-Jägerstad, M. (2003): HPLC determination of folates in raw and processed beetroots. Food Chemistry, 579-588.

Jennings, B. A.-Willis, G. (2015): How folate metabolism affects colorectal cancer development and treatment; a story of heterogeneity and pleiotropy. Cancer Letters 356, 224-230.

Lorizola, I. M.-Furlan, C. P. B.-Portovedo, M.-Milanski, M.Botelho, P. B.-Bezerra, R. M. N.-Sumere, B. R.-Rostagno, M. A.-Capitani, C. D. (2018): Beet Stalks and Leaves (Beta vulgaris L.) Protect Against High-Fat Diet-Induced Oxidative Damage in the Liver in Mice. Nutrients, 872.

Moat, S. J.-Lang, D.-McDowell, I. F. W.-Clarke, Z. L.-Madhavan, A. K.-Lewis, M. J.-Goodfellow, J. (2004): Folate, homocysteine, endothelial function. The Journal of Nutricional Biochemistry, 64-79.

Yoo, J. H.-Choi, G. D.-Kang, S. S. (2000): Pathogenicity of thermolabile methylenetetrahydrofolate reductase for vascular dementia. Arteriosclerosis, Thrombosis and Vascular Biology 20, 251-255. 
